\title{
Validation of analytical and continuum numerical methods for estimating the compressive strength of
} masonry

Paulo B. Lourenço \& J. Pina-Henriques

Dept. of Civil Engineering, University of Minho, Azurém, 4800-058 Guimarães, Portugal

\begin{abstract}
The advances in computational mechanics witnessed in the last decades have made available a large variety of numerical tools. Sophisticated non-linear models are now standard in several finite element based programs. This paper addresses the ability of continuum numerical methods, based on plasticity and cracking, as well as on analytical methods to provide reliable estimations of masonry compressive strength. In addition, a discussion on the load transfer between masonry components is presented and special attention is given to the numerical failure patterns. The results found overestimate the experimental strength and peak strain. Alternative modelling approaches that represent the micro-structure of masonry components are therefore needed.
\end{abstract}

Keywords: masonry, compression, micro-modelling, non-linear continuum models, finite elements. 


\section{Introduction}

Masonry compressive behaviour is of crucial importance for design and safety assessment purposes, since masonry structures are primarily stressed in compression. However, the compressive failure mechanism of quasi-brittle materials is rather complex, especially when compared with tensile failure. Compressive failure is characterized by the coalescence and growth of diffuse micro-cracks, accompanied by progressive localization of deformations and development of traction free macro-cracks. At ultimate stage, a distributed continuous pattern of splitting and shear cracks is formed, being responsible for failure, see Vonk [1].

The most relevant material property when dealing with compression is clearly the compressive strength. Experimentally, this property can be obtained according to the European norm EN 1052-1 [2], which specifies a testing specimen similar to the RILEM specimen, see Figure 1a. Mann and Betzler [3] observed that, initially, vertical cracks appear in the units along the middle line of the specimen, i.e., continuing the vertical joint. Upon increasing deformation, additional cracks appear, normally vertical cracks at the smaller side of the specimen that lead to failure by splitting of the prism. Experimental tests on representative masonry specimens are, however, relatively costly and not practical for design purposes. This fact persuaded researchers to investigate semi-empirical and analytical relations to predict masonry strength based on the components characteristics and on the type of masonry. Several semi-empirical relations can be gathered from the literature and the reader is referred to Rostampour [4], Kirtschigg [5], Haseltine [6] and Vermeltfoort [7] for details. Both European and North-American masonry 
codes / specifications $[8,9]$ use empirical relations to estimate the compressive strength of masonry from the compressive strength of unit and mortar.

Although empirical relations provide a safe basis for establishing design code provisions, little insight on the physical behaviour is obtained when compared to analytical methods. Today, it is well accepted by the research community that masonry compressive failure is mainly governed by the interaction between units and mortar. Assuming compatibility of strains between the components, the difference in stiffness leads, under uniaxial compressive loading, to a state of stress characterized by compression/biaxial tension of units and triaxial compression of mortar, see Figure 1b. This holds true, of course, when mortar is more deformable than units, which is generally the case of ancient masonry.

In the pioneer work of Hilsdsdorf [10], this phenomenon was firstly described and an equilibrium approach was developed to predict the masonry strength. Yet, Hilsdorf [10] assumed that failure of mortar coincides with failure of masonry, which is not necessarily true. In the theory proposed by Khoo and Hendry [11] this problem is overcome by considering a limit strain criterion based on the lateral strain exhibited by brick units at failure. Another relevant contribution was given by Ohler [12], which proposed an expression that in general shows good agreement with experimental data. Failure theories that allow following stress and strain evolution upon increasing loading have been also developed. Examples can be found in Francis et al. [13] and Atkinson et al. [14].

The present paper focuses on the ability of analytical methods and continuum nonlinear finite element models to reproduce the experimental behaviour of masonry under compression. A micro-modelling strategy incorporating units and mortar is followed, which is a powerful tool in the analysis of the composite material $[15,16]$. In addition, a 
discussion on the load transfer between the components upon increasing loading is presented and special attention is given to the numerical failure patterns obtained, which is an issue often disregarded in literature.

\section{Brief description of adopted experimental testing}

Binda et al. [17] carried out deformation controlled tests on masonry prisms with dimensions of $600 \times 500 \times 250 \mathrm{~mm}^{3}$, built up with nine courses of $250 \times 120 \times 55 \mathrm{~mm}^{3}$ solid soft mud bricks and $10 \mathrm{~mm}$ thick mortar joints. Three different types of mortar, namely $M 1, M 2$ and $M 3$, have been considered and testing aimed at the evaluation of the compressive properties of the prisms. For each type of mortar, a total of three prisms were tested.

The tests were carried out in a uniaxial testing machine MTS ${ }^{8} 311.01 .00$, with nonrotational steel plates and a maximum capacity of $2500 \mathrm{kN}$. The applied load was measured by a load cell located between the upper plate and the testing machine, while displacements were recorded by strain gauges located in the face of the specimens up to the peak load, see Figure 2. In addition, the average vertical displacement of each prism was also recorded with the machine in-built displacement transducer, permitting to capture the complete stress-strain diagram, including the softening regime. In this study, the prisms vertical strains and elastic moduli have been calculated from the transducer measured displacements. Teflon sheets were placed between the prisms and the loading plates in order to minimize restraining frictional stresses.

The characteristics of the masonry components in terms of compressive strength $f_{c}$, flexural tensile strength $f_{f}$, elastic modulus $E$ and coefficient of Poisson $v$ are given in Table 
1. The results obtained for the prisms are given in Table 2. Prisms $P 1, P 2$ and $P 3$ were built with mortars $M 1, M 2$ and $M 3$ of increasing strength, respectively. The experimental failure patterns found were rather similar despite of the type of mortar used [18]. Figure 3 depicts the typical failure pattern.

\section{Outline of the numerical model}

The simulations were carried out resorting to a basic cell, i.e., a periodic pattern associated to a frame of reference, see Figure 4. For the application envisaged here, units and mortar were represented by a structured continuum finite-element mesh. Yet, to reduce computational effort, only a quarter of the basic cell was modelled assuming adequate conditions for the in-plane boundaries, see Figure 5. In such a way, symmetry boundary conditions were assumed for the two sides along the basic cell symmetry axes and periodicity conditions for the two sides defining the external boundary of the basic cell.

It is certain that the boundary conditions and the test set-up affect the response of masonry under uniaxial compression. This is more significant in the post-peak regime but the peak load and pre-peak regime are also affected, see e.g. [3]. The choice of an appropriate test set-up resulted in the CEN specimen [2], which leads to the usage of moderately large specimens. The authors assumed that the experimental values from the actual testing program [17] aimed at obtaining the "true" compressive strength of masonry and, therefore, assumed the typical representative volume element (or basic cell) for such a material. Of course that the approach is only approximate of the real geometry and the obtained numerical response is phenomenological. This means that an exact comparison in terms of experimental and numerical failure patterns is not possible. In particular, 
localization of deformation, boundary effects of the specimen and non-symmetric failure modes are not captured by the numerical analysis. Again, these combined effects control mostly the post-peak response, which is not an issue in the present contribution.

Regarding the out-of-plane boundaries, three different approaches were considered: (a) plane-stress $P S$, (b) plane-strain $P E$ and (c) an intermediate state, here named enhancedplane-strain EPE. This last approach consists of modelling a thin out-of-plane masonry layer with 3D elements, imposing equal displacements in the two faces of the layer. Full 3D analyses with refined meshes and softening behaviour are unwieldy, and were not considered. Moreover, a recent paper indicates that enhanced plane stress analysis and 3D analysis provides very similar results [19].

Each approach corresponds to a different level of out-of-plane confinement. In plane-stress, out-of-plane stresses are precluded and the specimen can freely deform in this direction. This condition holds generally true at the surface of a specimen. On the contrary, in plane-strain, out-of-plane deformations are precluded, which is the limiting condition at the centre of a thick specimen. An intermediate state between these extreme conditions is also of interest in the evaluation of the model and the enhanced-plane-strain state was considered.

For $P S$ and $P E$, the masonry components were represented by approximately 1200 8-noded quadrilateral elements with 3700 nodes, totalling 7400 degrees of freedom. $3 \times 3$ Gauss integration was adopted. The material behaviour was described by a composite plasticity model with a Drucker-Prager yield criterion in compression and a Rankine yield criterion in tension [20,21]. The inelastic behaviour exhibits a parabolic hardening/softening diagram in compression and an exponential-type softening diagram in 
tension. The material behaves elastically up to one-third of the compressive strength and up to the tensile strength.

For $E P E$, modelling of the cell was carried out using approximately 90020 -noded brick elements with 6650 nodes, totalling 13300 degrees of freedom (note that the tying adopted for the out-of-plane degrees of freedom, mean that a basically 2D model is used). $3 \times 3 \times 3$ Gauss integration was adopted. The material model used in $2 \mathrm{D}$ simulations is not available for $3 \mathrm{D}$ models and a combined model with traditional smeared crack model in tension [22], specified as a combination of tension cut-off (two orthogonal cracks), tension softening and shear retention, and Drucker-Prager plasticity in compression had to be used [20]. The models in tension provide comparable results [23] but the plasticity based model is numerically more robust.

The loading scheme adopted in the simulations consisted in applying a vertical compressive stress at the upper and lower boundaries of the basic cell. The DIANA® finite element code [20] was adopted to carry out the simulations, being the non-linear equilibrium equations that arise from the finite element discretization solved using an incremental-iterative regular Newton-Raphson method, with arc-length control and linesearch technique.

\section{Definition of the model parameters}

The parameters were obtained, whenever possible, from the experimental tests. However, most of the inelastic parameters were unknown and had to be estimated from 
other tests. Despite the effort made in the last decades, micro-simulations are often hindered by the lack of experimental data on the non-linear properties of the components.

The elastic material properties adopted were previously given in Table 1 and the inelastic properties are fully detailed in Table 3. Here, $c$ is the cohesion, $f_{t}$ is the tensile strength, $\phi$ is the friction angle, $\psi$ is the dilatancy angle, $G f_{t}$ is the tensile fracture energy and $G f_{c}$ is the compressive fracture energy. The value adopted for the friction angle was $10^{\circ}$ (a larger value in plane-stress would implicate an overestimation of the biaxial strength) and, for the dilatancy angle, a value of $5^{\circ}$ was assumed [24]. The values assumed for the fracture energy have been based in recommendations supported in experimental evidence $[25,26]$ and practical requirements to ensure numerical convergence. Severe convergence problems were found due to the strongly inhomogeneous stress and strain fields that result from the analysis, especially in the case of prism $P 1$, which features very large differences between the properties of units and mortar.

\section{Numerical results and comparison with experimental data}

\subsection{Stress-strain diagrams}

The boundary conditions imposed on the model lead to equal normal displacements along each boundary but non-uniform stress fields. In this way, the average stress applied on the cell results from the integral of stresses over the upper and bottom boundaries divided by their length. The strain is the measure of an equivalent homogenised basic cell. The comparison between the numerical and experimental stress-strain diagrams is given in 
Figure 6. Here it is shown that EPE response is always between the extreme responses obtained with $P S$ and $P E$. For this reason, enhanced-plane-strain is accepted as the reference solution for the numerical analysis in the rest of the paper. It is further noted that the difference between the strength values predicted in $P S$ and $P E$ conditions increase with larger compressive strength ratios $f_{c, \text { unit }} / f_{c, \text { mortar }}$. This can be explained by the fact that weak mortar joints fail at a very early stage if no out-of-plane confinement is present.

Another important aspect is that the numerical strength largely overestimates the experimental strength in all the three prisms, even if the peak strain is well reproduced by the numerical analysis. Comparing the results in terms of stiffness, it is possible to observe that the numerical response is much stiffer than the experimental response. This can be explained by the fact that the stiffness of the mortar inside the composite is different from the stiffness of mortar specimens cast separately due to different laying and curing conditions, see e.g. Lourenço [15]. This complex issue requires advanced experimental research on the mortar interface. Preliminary results indicate the presence of a clear weak interface between the mortar and brick [27]. This would require a more complex simulation with one additional material.

The difficulty in evaluating the stiffness of the mortar inside the composite represents a severe drawback of detailed micro-models. To reproduce correctly the experimental elastic stiffness of the masonry prisms, the elastic modulus of the mortar had to be adjusted by inverse fitting. An estimate of the value of the adjusted stiffness can be obtained, disregarding the interaction unit-mortar, from

$$
\Delta_{y, M}=\Delta_{y, u}+\Delta_{y, m}
$$


where $\Delta_{y, M}$ is the vertical displacement of a masonry prism, $\Delta_{y, u}$ is the vertical displacement contribution of the units and $\Delta_{y, m}$ is the vertical displacement contribution of the mortar joints. This equation reads, after some manipulation,

$$
E_{a d j}=\frac{h_{m} E_{M} E_{u}}{E_{u}\left(h_{m}+h_{u}\right)-E_{M} h_{u}}
$$

here, $E_{a d j}$ is the adjusted elastic modulus of the mortar, $E_{u}$ is the elastic modulus of the units, $E_{M}$ is the elastic modulus of the composite given in Table $2, h_{m}$ is the joint thickness and $h_{u}$ is the height of the units.

The adjusted elastic moduli assumed in the new simulations are given in Table 4. In addition, the ratios between the adjusted $E_{a d j}$ and experimental $E_{\text {exp }}$ elastic moduli are also shown, indicating that the adjusted elastic modulus ranges between $6 \%$ and $30 \%$ of the values recorded experimentally in mortar prisms. Here, it is noted that the relation between adjusted and mortar prism elastic modulus decreases with the mortar strength. The obtained adjusted stress-strain diagrams are illustrated in Figure 7, together with the results obtained with the experimental stiffness for a better comparison. The strength values are similar using either the experimental mortar stiffness or the adjusted value but a dramatic difference in the peak strain was found. In fact, for the adjusted mortar stiffness, the numerical peak strain largely overestimates the experimental value and the difference increases with increasing mortar strength.

The possibility of adjusting also the mortar strength was not considered because a direct relation between strength and stiffness cannot be established in such a complex case of mortar curing, compaction and moisture exchange. 


\subsection{Failure patterns}

Failure patterns are an important feature when assessing numerical models. Figure 8 to Figure 13 depict the deformed meshes at failure for the three types of prism in $P S, P E$ and $E P E$ conditions. In addition, the contour of the minimum principal plastic strains is also given in the case of $E P E$.

The failure mechanisms obtained depend obviously on the modelling strategy adopted. This is numerically correct but physically non-realistic, even if it is an issue often disregarded. Therefore, the analysis of the failure patterns obtained in the $P S, P E$ and $E P E$ conditions easily indicates acceptable out-of-plane boundary effects (or modelling strategies). In $P S$ conditions, prisms $P 1$ and $P 2$ fail due to crushing of the bed joints while prism $P 3$ fails due to vertical cracks arising in the bed-joints, together with diagonal "crushing" that crosses the units and connects the non-aligned vertical cracks (it is noted that crushing in the centre of the units is more profound), see Figure 8a, 10a and 12a. These failure patterns are unacceptable, see also Figure 3, indicating that $P S$ conditions cannot be generally used for simulation of compressive failure of masonry.

In $P E$ conditions, failure of prisms $P 1$ and $P 2$ is mainly governed by vertical cracks developing close to the centre of the units and in the head-joints. Prism $P 3$, instead, fails due to diffuse vertical cracking crossing both units and joints, combined with crushing of the centre of the units, see Figure $8 \mathrm{~b}, 10 \mathrm{~b}$ and $12 \mathrm{~b}$. These are realistic failure patterns, as vertical cracks in masonry usually appear to arise in the head joints, followed by vertical crack propagation across the units. 
In $E P E$ conditions, prism $P 1$ fails mainly due to the development of vertical cracks in the centre of the units and along the head-joints, being the mortar in the bed-joints severely damaged, see Figure 9.. Prisms $P 2$ and $P 3$ fails due to the development of several vertical cracks arising in the bed joints together with compressive damage of the units, especially at the centre, see Figure 11 and Figure 13. Again, these are realistic failure patterns, as vertical cracks in masonry usually appear to arise in the head joints, followed by vertical crack propagation across the units.

These results indicate that, from a point of view of failure pattern, $P E$ and $E P E$ conditions seem to be possible. Nevertheless, $P E$ provides much worse results in terms of failure loads when compared with $E P E$, as shown in the previous section.

\subsection{Stress distribution}

Insight on the stress distribution upon increasing loading can be provided by stress diagrams along different sections of the cell, see Figure 14. Prism $P 1$ has been chosen as an example because it has a relatively strong unit and a rather weak mortar as often occurs in ancient masonry. Three different load levels were considered, each one corresponding to a different branch of the stress-strain diagram.

Severe non-linear behaviour and stress redistribution has been found, with failure not occurring when the maximum stress is attained at a given point of the discretization. As expected, Figure 14a indicates that mortar is heavily triaxially compressed and the units are under combined compression-biaxial tension. A decrease of vertical compressive stresses in the bed-joints is observed near the head-joints due to the low stiffness of the mortar, see Figure 14b. This unloading effect increases closer to collapse, due to inelastic behaviour of 
the head joints. Moreover, in Figure 14c, it is possible to observe that increasing stress concentration develops at the unit edges as load increases and the neighbouring head-joint fails. Also due to increasing damage in the head-joint, the centre of the units exhibit a decrease of compressive vertical stresses as the load increases, resulting in a failure of the unit with horizontal offset with respect to the head joints.

\section{Calculations using simplified models}

This section contains an analytical interpretation of the experimental results, with simple calculations being used to predict the compressive strength $f_{c}$ of the prisms. The following equations have been utilized:

(a) equation proposed by Francis et al. [13]

$$
f_{c}=\frac{1}{1+\frac{\alpha \phi\left(\beta v_{m}-v_{u}\right)}{\beta\left(1-v_{m}\right)}} \cdot f_{c, u}
$$

where the parameters $\alpha, \beta$ and $\phi$ read

$$
\alpha=\frac{h_{m}}{h_{u}} \quad ; \quad \beta=\frac{E_{u}}{E_{m}} \quad ; \quad \phi=\frac{f_{c, u}}{f_{t, u}}
$$


(b) equation proposed by Khoo and Hendry [11]

$$
A f_{c}^{3}+B f_{c}^{2}+C f_{c}+D=0
$$

where the parameters $A, B, C$ and $D$ are given by

$$
\begin{aligned}
& A=-0.2487 f_{t, u}\left(\frac{1}{f_{c, u}}\right)^{3}+0.0018 \alpha\left(\frac{1}{f_{c, m}}\right)^{2} \\
& B=1.2781 f_{t, u}\left(\frac{1}{f_{c, u}}\right)^{2}-0.0529 \alpha\left(\frac{1}{f_{c, m}}\right) \\
& C=-2.0264 f_{t, u}\left(\frac{1}{f_{c, u}}\right)-0.1126 \alpha \\
& D=0.9968 f_{t, u}+0.1620 \alpha f_{c, m}
\end{aligned}
$$

(c) equation proposed by Ohler [12]

$$
f_{c}=f_{c, m}+\frac{s f_{c, u}-f_{c, m}}{1+\frac{t h_{m} f_{c, u}}{m h_{u} f_{t, u}}}
$$

where $s$ and $t$ are parameters defining the unit failure envelope and $m$ is the slope of the mortar failure envelope. The values presented by Ohler [12] for these parameters are given in Table 5 and Table 6, respectively. 
(d) equation provided by Eurocode 6 [8]

$$
f_{c, k}=K f_{c, u}^{0.7} f_{c, m}^{0.3}
$$

where $f_{c, k}$ is the masonry characteristic compressive strength and $K$ is a parameter that depends on the type of unit and on the type of masonry.

(e) equation provided by ACI Specification for Masonry Structures [9]

$$
f_{m}^{\prime}=A\left(400+B f_{c, u}\right)(\mathrm{psi})
$$

where $f^{\prime}{ }_{m}$ is the specified compressive strength, in psi, $A=1$ (inspected masonry) and $B=$ 0.2 for Type N Portland cement-lime mortar or $B=0.25$ for Type S or M Portland cementlime mortar.

In the equations above, $f_{c, u}$ and $f_{c, m}$ are the compressive strength of units and mortar, $f_{t, u}$ is the tensile strength of units, $E_{u}$ and $E_{m}$ are the elastic modulus of units and mortar, $v_{u}$ and $v_{m}$ are the coefficients of Poisson of units and mortar and $h_{u}$ and $h_{m}$ are the units height and mortar thickness.

The first three equations follow from equilibrium methods under the assumption that units are uniaxially compressed - biaxially tensioned while mortar is triaxially compressed, see Hendry [28] for a comprehensive review on these methods. For this reason, these equations are only applicable when the unit stiffness exceeds the mortar stiffness, which is the case of all the three prisms considering the mortar adjusted elastic 
modulus. However, in the case of prism $P 3$, the very large ratio between the mortar and unit strengths precludes the application of the equations proposed by Khoo \& Hendry [11] and Ohler [12], since their formulation only considers explicitly the mortar strength rather than the mortar elastic properties. On the contrary, the equation proposed by Francis et al. [13] only considers the mortar elastic properties and, thus, was also applied to prism $P 3$.

Equation (8) is provided by Eurocode 6 [8] and has empirical nature. In this formula, the parameter $K$ equals $0.8 \times 0.55=0.44$ for the application here envisaged. It is also noted that the mortar strength for prism $P 3$ was assumed equal to $20 \mathrm{~N} / \mathrm{mm}^{2}$, which is the maximum strength permitted by the code. The mean value of the masonry compressive strength $f_{\mathrm{c}}$ was calculated from the characteristic value $f_{c, k}$ assuming $f_{c}=f_{c, k}+1.64 \sigma$, where $\sigma$ is the standard deviation. A coefficient of variation $C V$ equal to $\sigma f_{c}=10 \%$ was adopted.

Equation (9) is part of the unit strength method provided by ACI for masonry structures and is also of empirical nature. The parameter $B$ was assumed to equal 0.2 in the case of mortar $M 1$ and 0.25 in the case of mortars $M 2$ and $M 3$. The mean value of the masonry compressive strength $f_{c}$ was calculated from the specified strength $f^{\prime}{ }_{m}$ assuming $f_{c}$ $=f^{\prime}{ }_{m}+1.34 \sigma$. Also here, a $C V$ equal to $10 \%$ was considered.

The results obtained are given in Table 7. All the three equilibrium formulas overestimate the experimental strength, especially the equation proposed by Francis et al. [13]. On the contrary, EC 6 and ACI empirical formulas predict, as expected, a value lower than the experimental strength, with ACI formula providing a better estimate for the low strength mortar prisms $P 1$ and EC6 formula predicting a more accurate value for the high strength mortar prisms P3. It is further noted that Francis et al. [13] equation yielded decreasing masonry strength values for prisms built with increasing strength mortar. This is 
not realistic and can be explained by the high sensibility of Francis et al. [13] equation to the values of the coefficient of Poisson, which can be considered a drawback of this method given the difficulties in determining objectively such values. If a coefficient of Poisson equal to 0.2 is assumed for the units and the three types of mortar, the decreasing trend is no longer observed and the masonry strength values obtained are 22.1, 22.5 and 22.8 $N / \mathrm{mm}^{2}$ for prisms $P 1, P 2$ and $P 3$, respectively.

It is also noted that the numerical simulations always provide over-strength, when compared to analytical solutions $[11,12]$ based in equilibrium approaches. This indicates that homogenised equilibrium approaches must be used carefully and new approaches are required.

\section{Conclusions}

The paper addresses the ability of continuum models based in plasticity and cracking to reproduce the experimental compressive behaviour of masonry. The results obtained with simulations of compression tests on masonry prisms allow to conclude that: (a) continuum finite element modelling largely overestimates the strength and peak strain of the prisms; (b) plane-stress, plane-strain and "enhanced-plane-strain" lead to different strengths and different failure mechanisms. Plane-stress leads to unacceptable failure mechanisms and plane-strain leads to very high failure loads. Therfore, the usage of 3D models or enhanced-plane-strain models is recommended; (c) simplified methods to predict the strength based on elastic considerations provide results different from advanced numerical analyses. This last conclusion has also been confirmed by [16], indicating that 
experimental testing or rather conservative empirical formulae at the only possible solution at the present state of knowledge.

In short, as a result of this paper, it is believed that standard continuum finite element modelling, based on plasticity and cracking, and analytical formulations cannot be used to adequately forecast the mechanics of masonry and to adequately predict the strength from the properties of the components. In order to further advance in this direction, it is necessary to: (a) seek alternative models to represent the micro-structure of masonry components, see e.g. [29]; (b) carry out an advanced experimental programme to characterize the mechanical behaviour of mortars inside a masonry composite. 


\section{Acknowledgements}

The financial support by the Portuguese Foundation for Science and Technology (FCT) under grant SFRH/BD/5002/2001 awarded to J. Pina-Henriques is gratefully acknowledged.

\section{References}

[1] Vonk R. A micromechanical investigation of softening of concrete loaded in compression. Heron 1993;38(3).

[2] CEN. EN 1052-1, Methods of test for masonry: Determination of compressive strength. Brussels, Belgium, 1999.

[3] Mann W, Betzler M. Investigations on the effect of different forms of test samples to test the compressive strength of masonry. In: Proc $10^{\text {th }}$ Int Brick/Block Masonry Conf. Calgary, Canada, 1994. p. 1305-1313.

[4] Rostampour M. Aspects of the design of multi-storey buildings in light-weight concrete blockwork. PhD thesis. University of Edinburgh, UK, 1973.

[5] Kirtschigg K. On the failure mechanism of masonry subject of compression. In: Proc $7^{\text {th }}$ Int Brick/Block Masonry Conf. Melbourne, Australia, 1985. p. 625-629.

[6] Haseltine B. International rules for masonry and their effect on the UK. Masonry International 1987;1(2):41-43.

[7] Vermeltfoort A. Compression properties of masonry and its components. In: Proc $10^{\text {th }}$ Int Brick/Block Masonry Conf. Calgary, Canada. p. 1433-1442.

[8] CEN. Eurocode 6: Design of masonry structures. prEN 1996-1-1:2002. Brussels, Belgium, 2003. 
[9] ACI. ACI 530.1-02, Commentary on specification for masonry structures. Manual of Concrete Practice. Detroit, USA, 2004.

[10] Hilsdorf $\mathrm{H}$. An investigation into the failure mechanism of brick masonry loaded in uniaxial compression. Designing, Engineering and Construction with Masonry Products. Houston: F.B. Jonhson; 1969.

[11] Khoo C, Hendry A. A failure criterion for brickwork in axial compression. In: Proc $3^{\text {rd }}$ Int Brick/Block Masonry Conf. Essen, Germany, 1973. p. 139-145.

[12] Ohler A. Zur berechnung der druckfestigeit von mauerwerk unter berucksichtigung der mehrachsigen spannungszustande in stein und mortel. Bautechnik 1986; 5.

[13] Francis A, Horman C, Jerrems L. The effect of joint thickness and other factors on the compressive strength of brickwork. In: Proc $2^{\text {nd }}$ Int Brick/Block Masonry Conf. Stoke-on-Trent, UK, 1971. p. 31-37.

[14] Atkinson R, Noland J, Abrams D. A deformation failure theory for stack-bond brick masonry prisms in compression. In: Proc $7^{\text {th }}$ Int Brick/Block Masonry Conf. Melbourne, Australia, 1985. p. 577-592.

[15] Lourenço PB. Computational strategies for masonry structures. PhD thesis. Delft University of Technology, The Netherlands, 1996. Available from www.civil.uminho.pt/masonry.

[16] Brencich A, Gambarotta L. Mechanical response of solid clay brickwork under eccentric loading. Part I: Unreinforced masonry. Materials and Structures 2005;38(276):257-266. 
[17] Binda L, Fontana A, Frigerio G. Mechanical behaviour of brick masonries derived from unit and mortar characteristics. In: Proc $8^{\text {th }}$ Int Brick/Block Masonry Conf. Dublin, Ireland, 1988. p. 205-216.

[18] Frigerio G, Frigerio P. Influence of the components and surrounding environment in the mechanical behaviour of brick masonry (in Italian). Graduation thesis. Politecnico di Milano, Italy, 1985.

[19] Berto, L.,Saetta, A., Scotta, R., Vitaliani, R. Failure mechanisms of masonry prism loaded in axial compression: computational aspects. Materials and Structures; 38: 249-256.

[20] TNO Building and Construction Research. Diana Finite Element Code, Version 7.2. Delft, The Netherlands, 1999.

[21] Feenstra P. Computational Aspects of Biaxial Stress in Plain and Reinforced Concrete. PhD thesis. Delft University of Technology, The Netherlands, 1993.

[22] Rots JG. Computational Modeling of Concrete Fracture. PhD thesis. Delft University of Technology, The Netherlands, 1988.

[23] Lourenço PB, Rots JG, Feenstra P. A tensile "Rankine" type orthotropic model for masonry. In: Proc $3^{\text {rd }}$ Int Symposium on Computer Methods in Structural Masonry, Lisbon, Portugal, 1995. p. 167-176.

[24] Vermeer PA, de Borst R. Non-associated plasticity for soils, concrete and rock. Heron 1984;29(4).

[25] Lourenço PB. A user/programmer guide for the micro-modelling of masonry structures. Report 03.21.1.31.35. Delft University of Technology, the Netherlands, 1996. Available from www.civil.uminho.pt/masonry. 
[26] CEB-FIP. Bulletin D’Information 213/214: Model code 1990. London: T Telford; 1993.

[27] Groot, C. Effects of water on mortar-brick bond. PhD Thesis. Delft University of Technology, the Netherlands, 1993.

[28] Hendry A. Structural masonry. London: McMillan Education; 1990.

[29] Pina-Henriques, JL, Lourenço, PB. Masonry compression: a numerical investigation at meso-level, Engineering Computations, 23(4), 2006. 


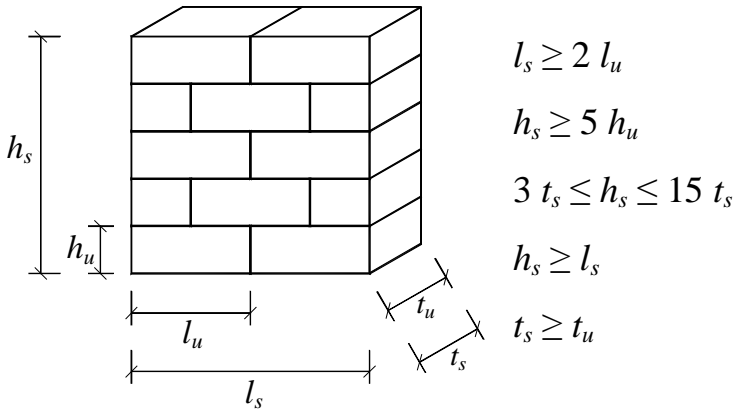

(a)

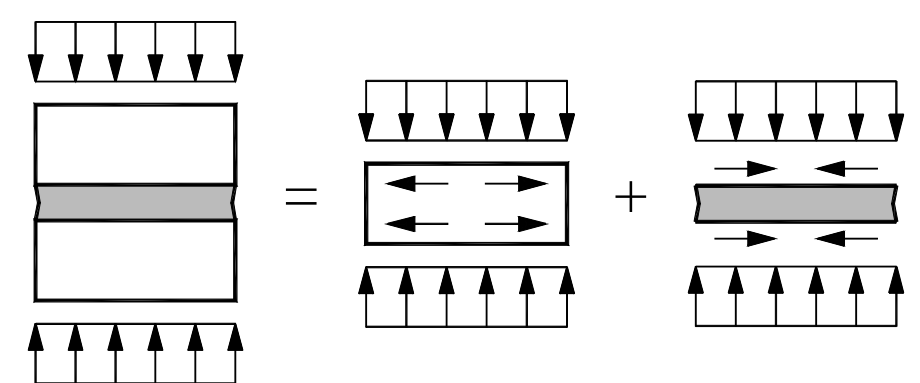

(b)

Figure 1 - Uniaxial behaviour of masonry: (a) test specimen according to the European standards (for units with $l_{u} \leq 300 \mathrm{~mm}$ and $h_{u} \leq 150 \mathrm{~mm}$ ) [2] and (b) schematic plane representation of stresses in masonry components. Here, the subscript $u$ refers to the unit and the subscript $s$ refers to the specimen. 

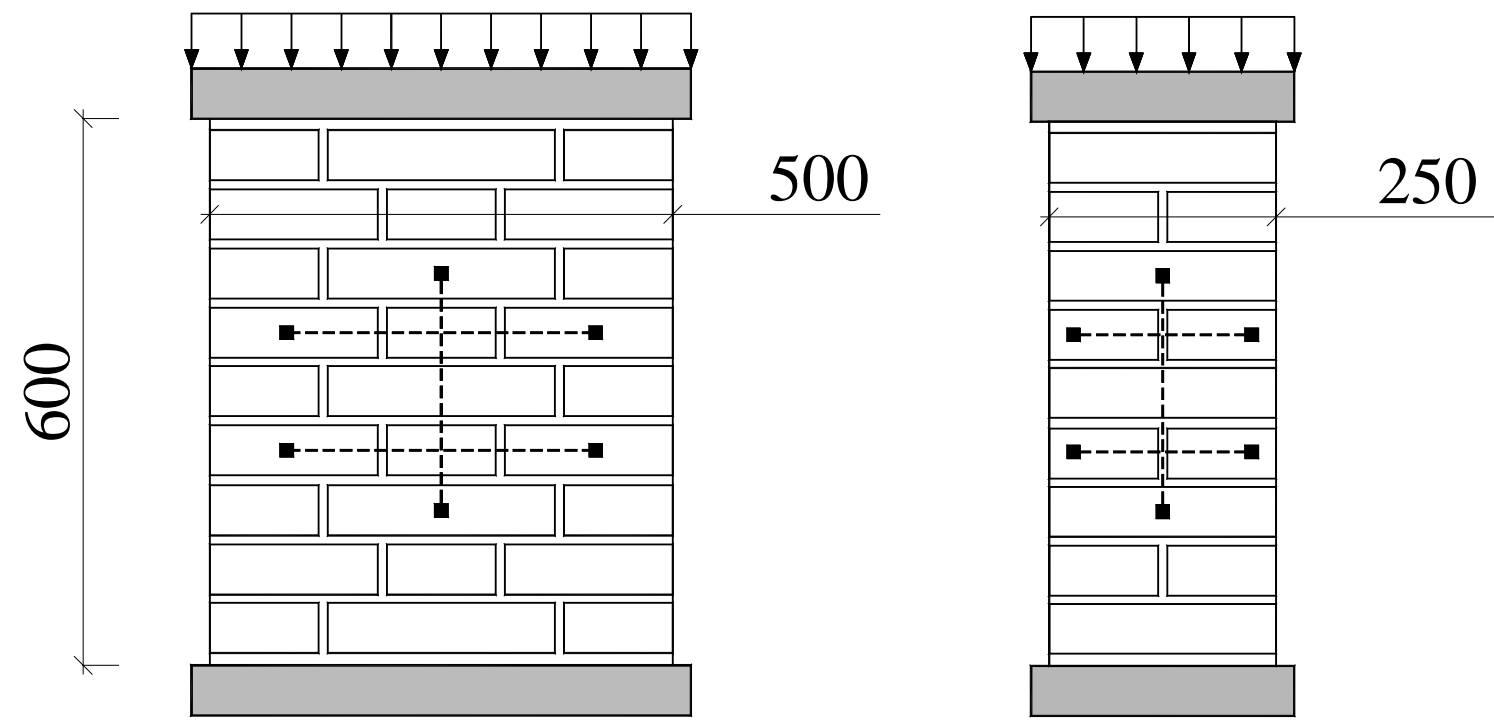

Figure 2 - Tested masonry wallets and location of strain gauge measurements [17]. The dimensions are in $\mathrm{mm}$. 

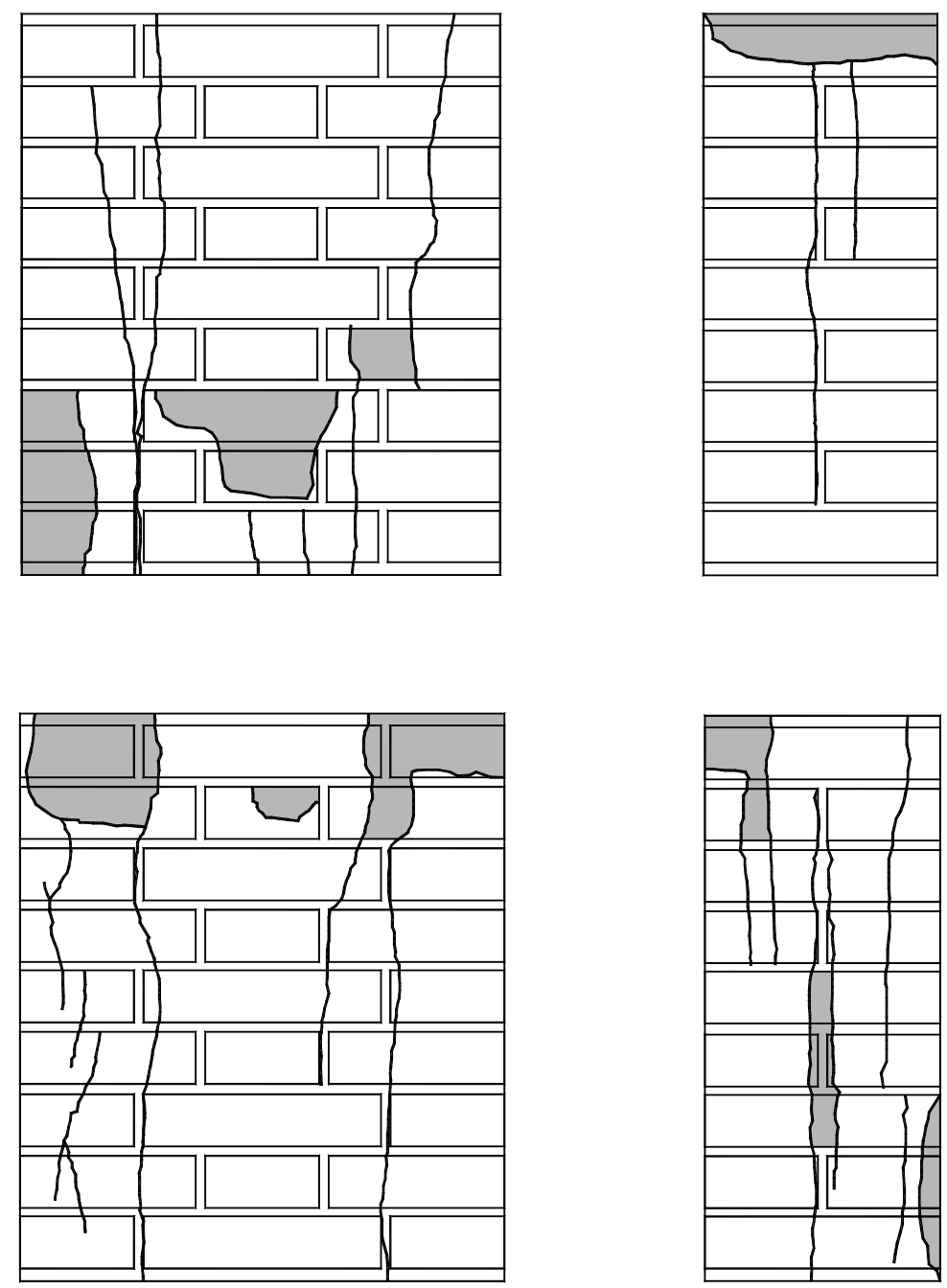

Figure 3 - Typical experimental failure patterns [18]. The shaded areas indicate spalling of material. 


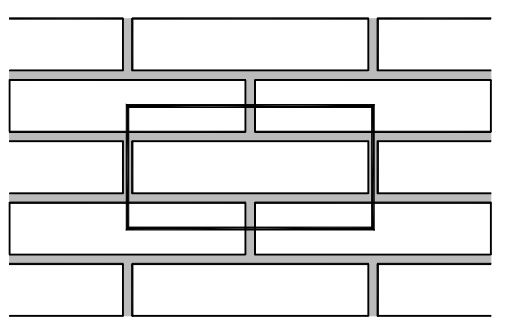

(a)

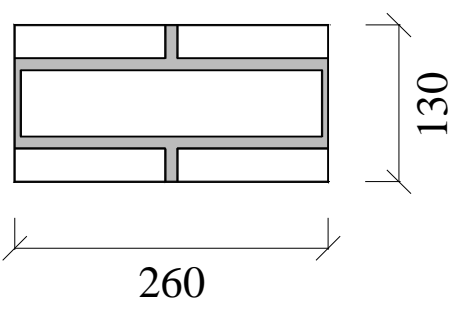

(b)

Figure 4 - Definition of basic cell: (a) running bond masonry and (b) geometry. 


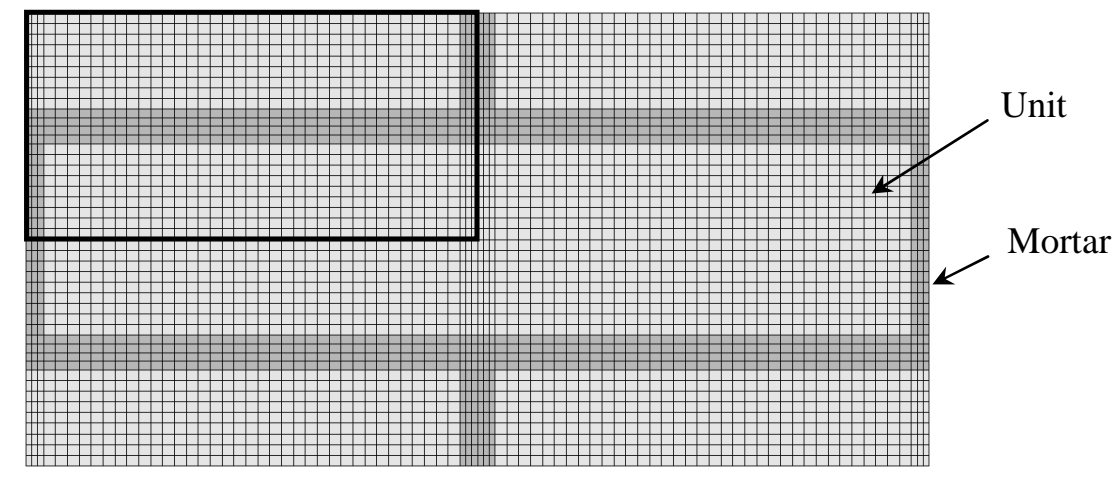

Figure 5 - Model used in the simulations (only the quarter indicated was simulated, assuming symmetry conditions). 


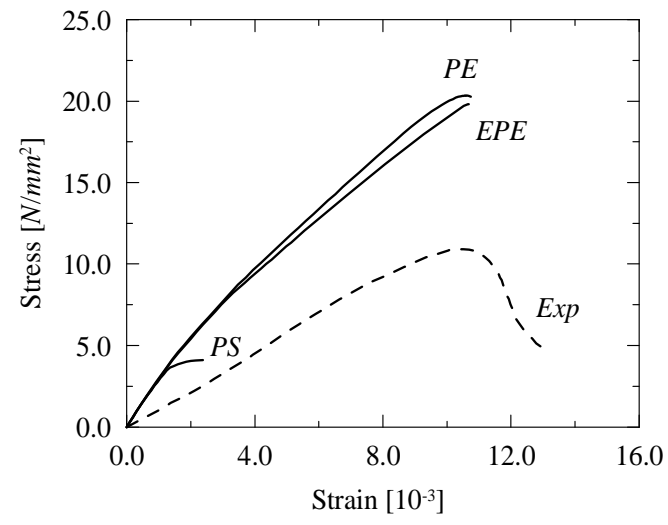

(a)

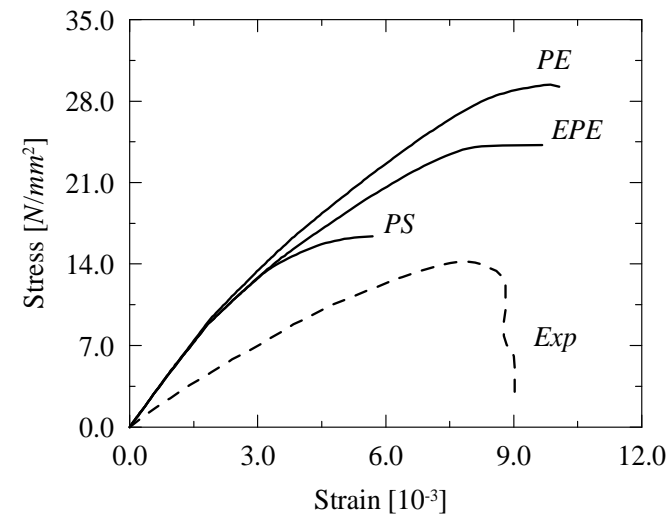

(b)

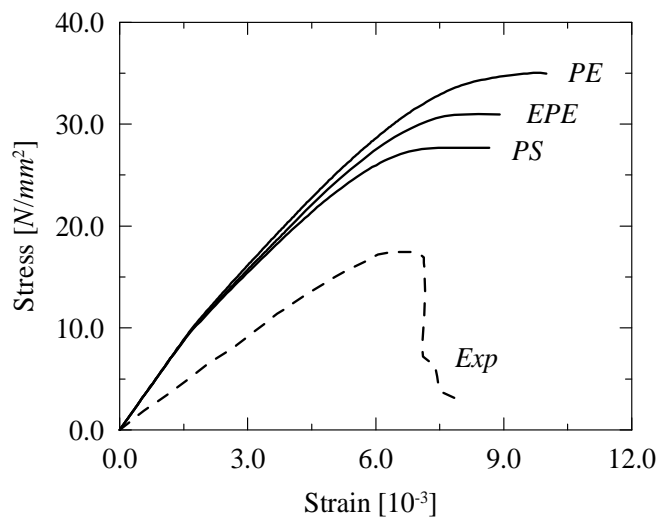

(c)

Figure 6 - Experimental and numerical stress-strain diagrams in $P S, P E$ and $E P E$ conditions for prisms: (a) $P 1$, (b) $P 2$ and (c) $P 3$. 


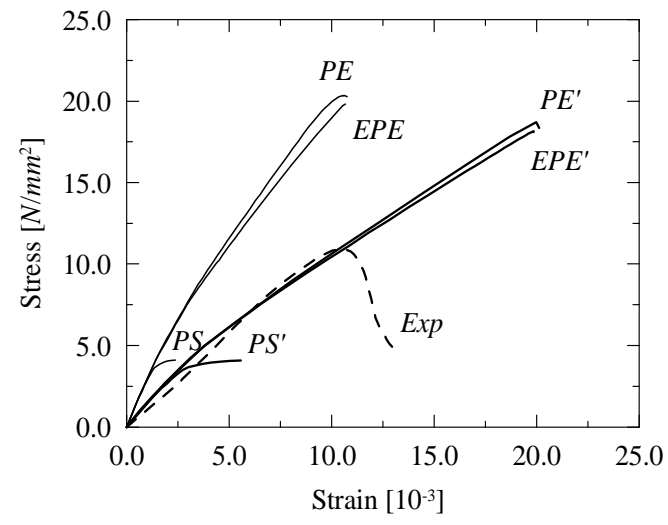

(a)

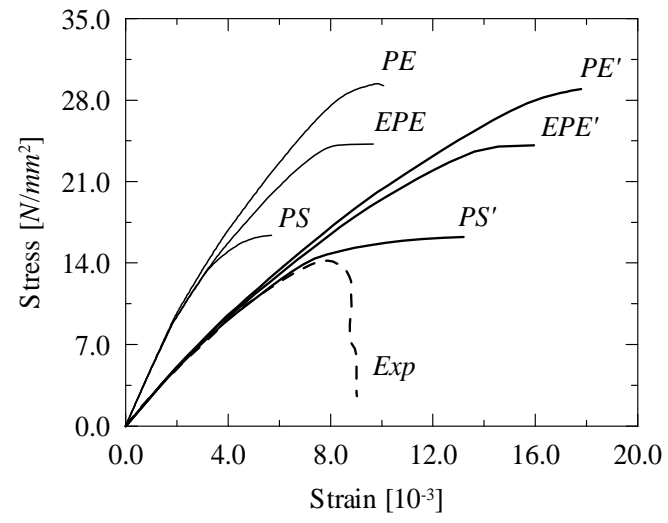

(b)

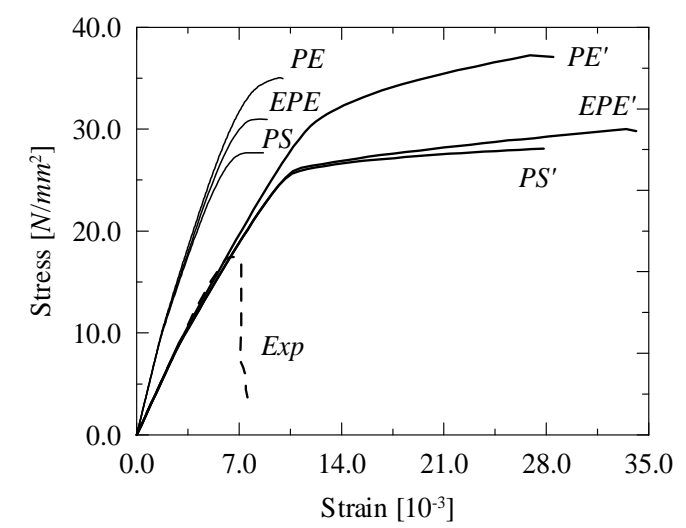

(c)

Figure 7 - Comparison between the stress-strain diagrams obtained with experimental (no superscript) and adjusted (' superscript) mortar stiffness values for prisms:

(a) $P 1$, (b) $P 2$ and (c) $P 3$. 


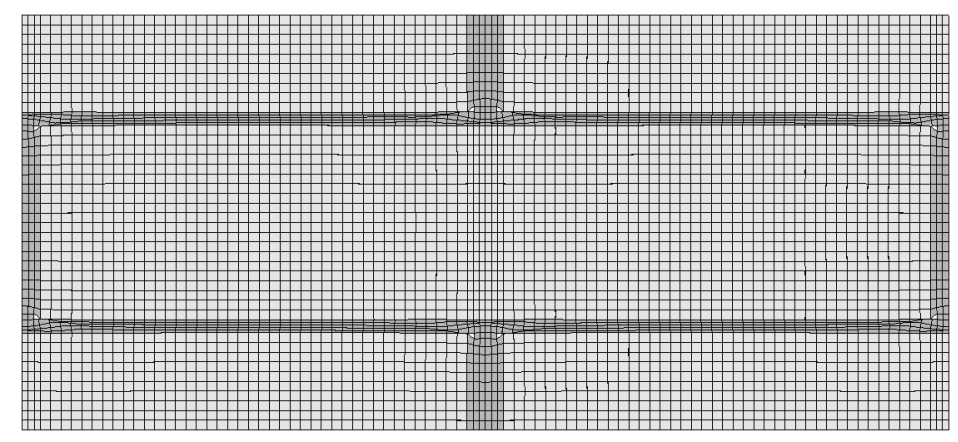

(a)

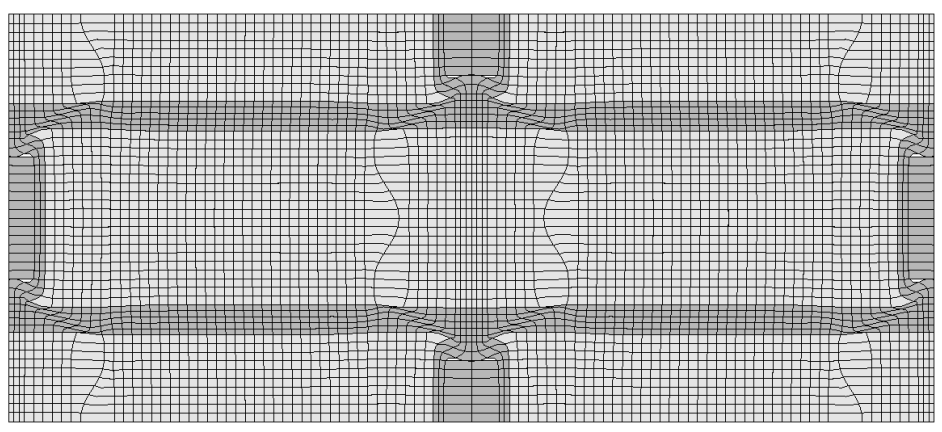

(b)

Figure 8 - Deformed (incremental) meshes at failure for prism P1: (a) $P S$ and (b) $P E$. 


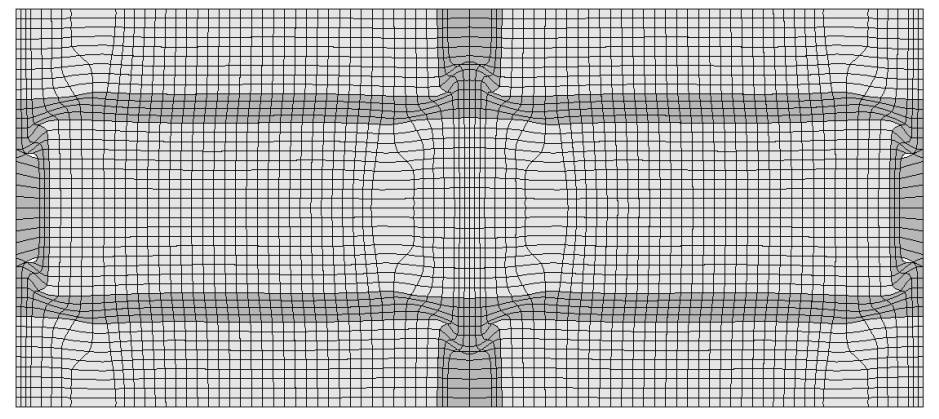

(a)

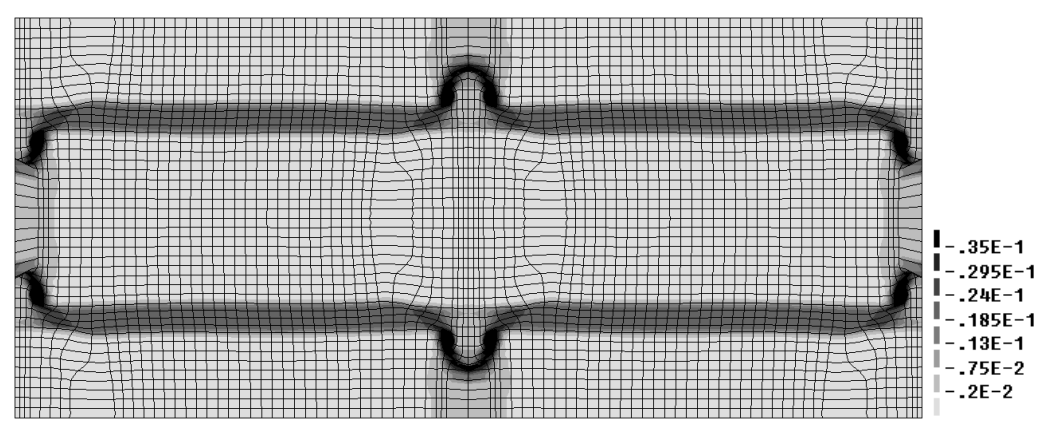

(b)

Figure 9 - Results obtained at failure for prism P1 in EPE: (a) deformed (incremental) mesh and (b) minimum principal plastic strains. 


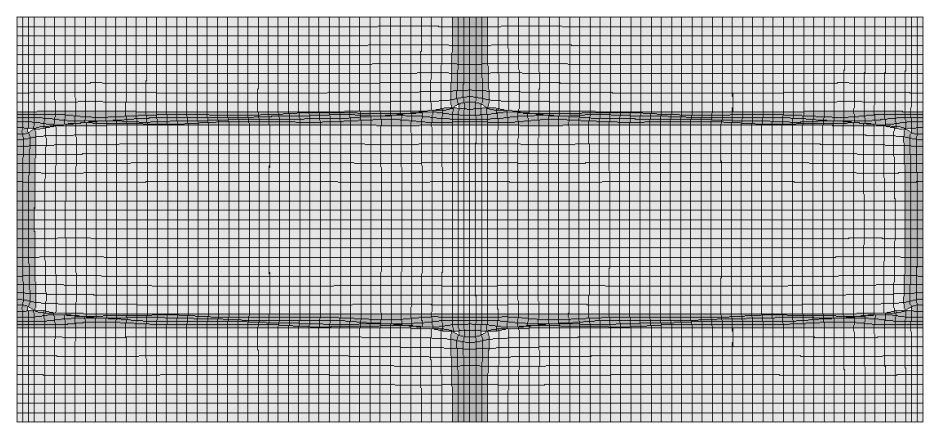

(a)

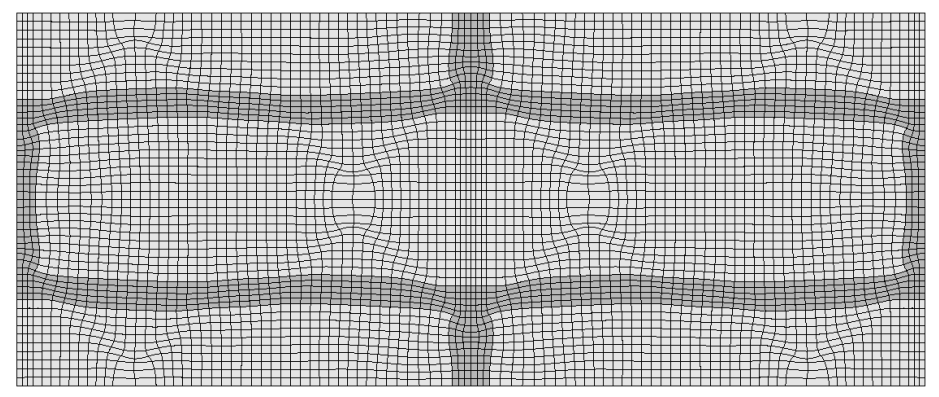

(b)

Figure 10 - Deformed (incremental) meshes at failure for prism $P 2$ : (a) $P S$ and (b) $P E$. 


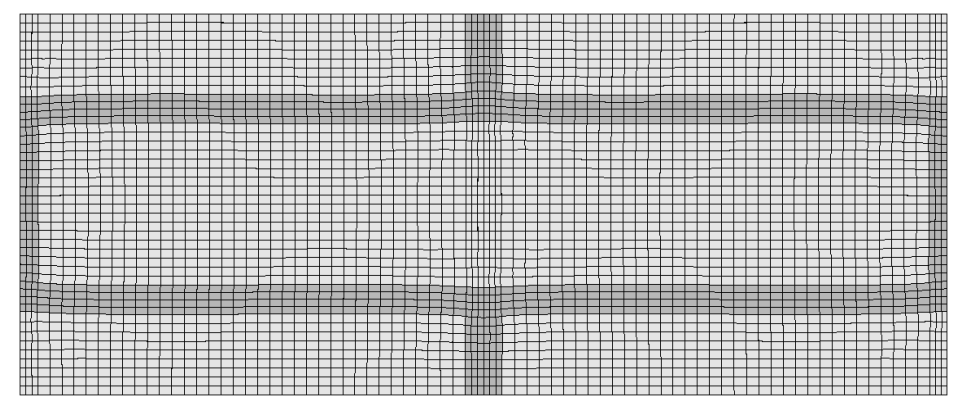

(a)

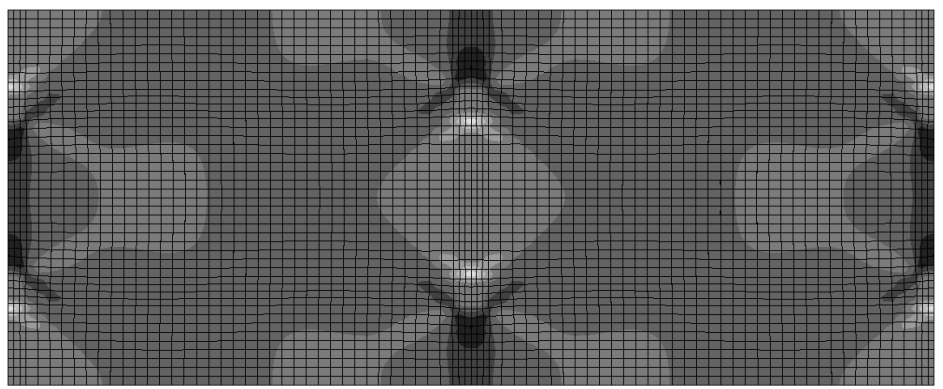

- $.5 \mathrm{E}-1$

$-.433 E-1$

$\mathrm{C}_{-.3 \mathrm{E}-1}^{-.367-1}$

$1-.233 \mathrm{E}-1$

$-.167 \mathrm{E}-1$

(b)

Figure 11 - Results obtained at failure for prism P2 in EPE: (a) deformed (incremental) mesh and (b) minimum principal plastic strains. 


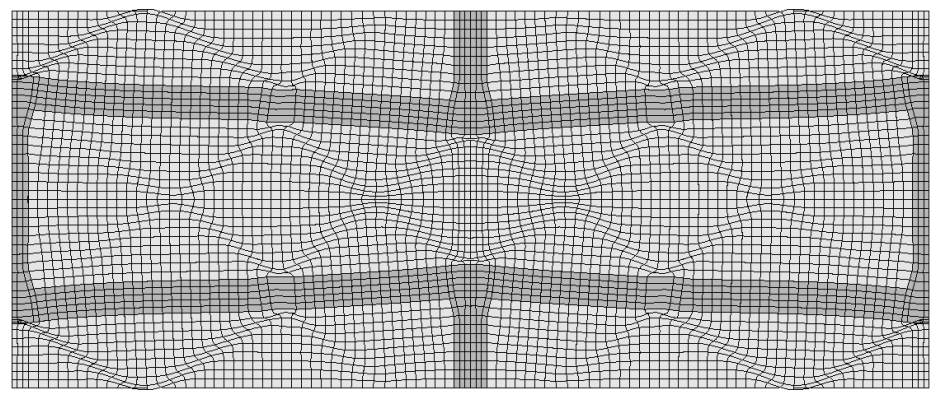

(a)

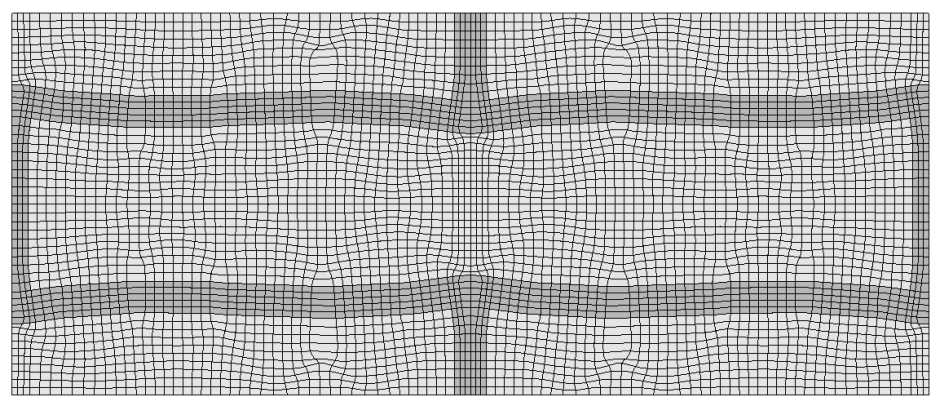

(b)

Figure 12 - Deformed (incremental) meshes at failure for prism P3: (a) PS and (b) PE. 


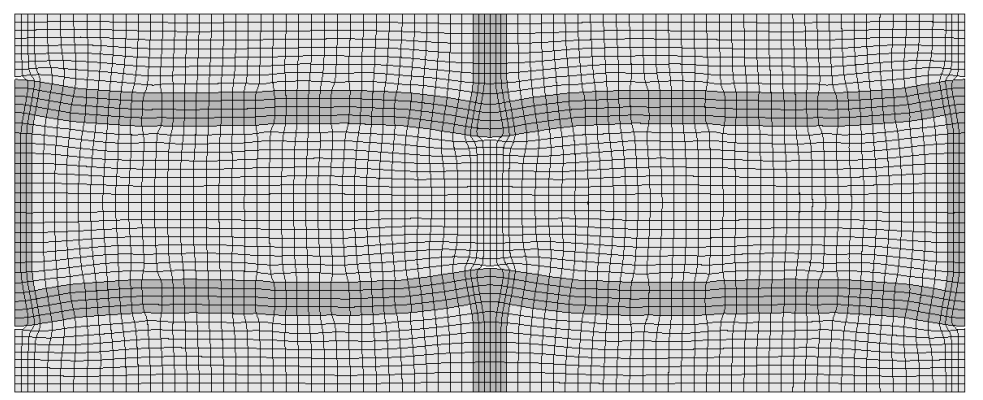

(a)

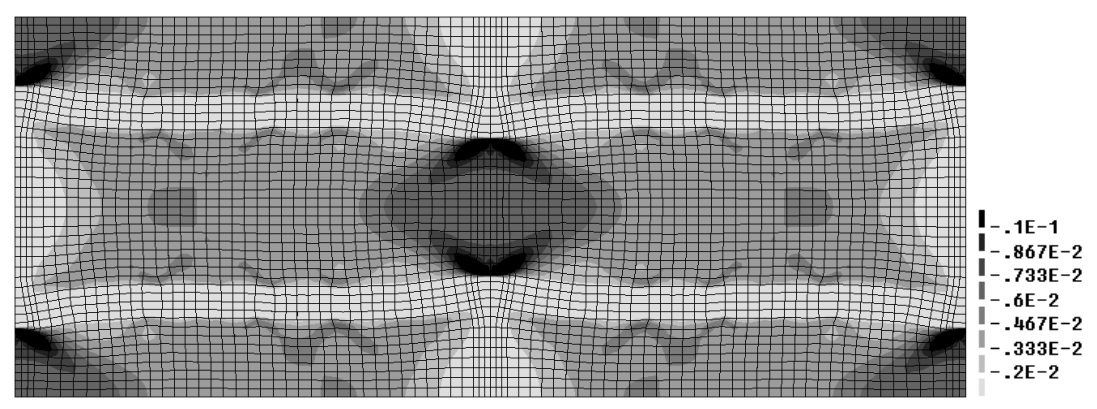

(b)

Figure 13 - Results obtained at failure for prism P3 in EPE: (a) deformed (incremental) mesh and (b) minimum principal plastic strains. 

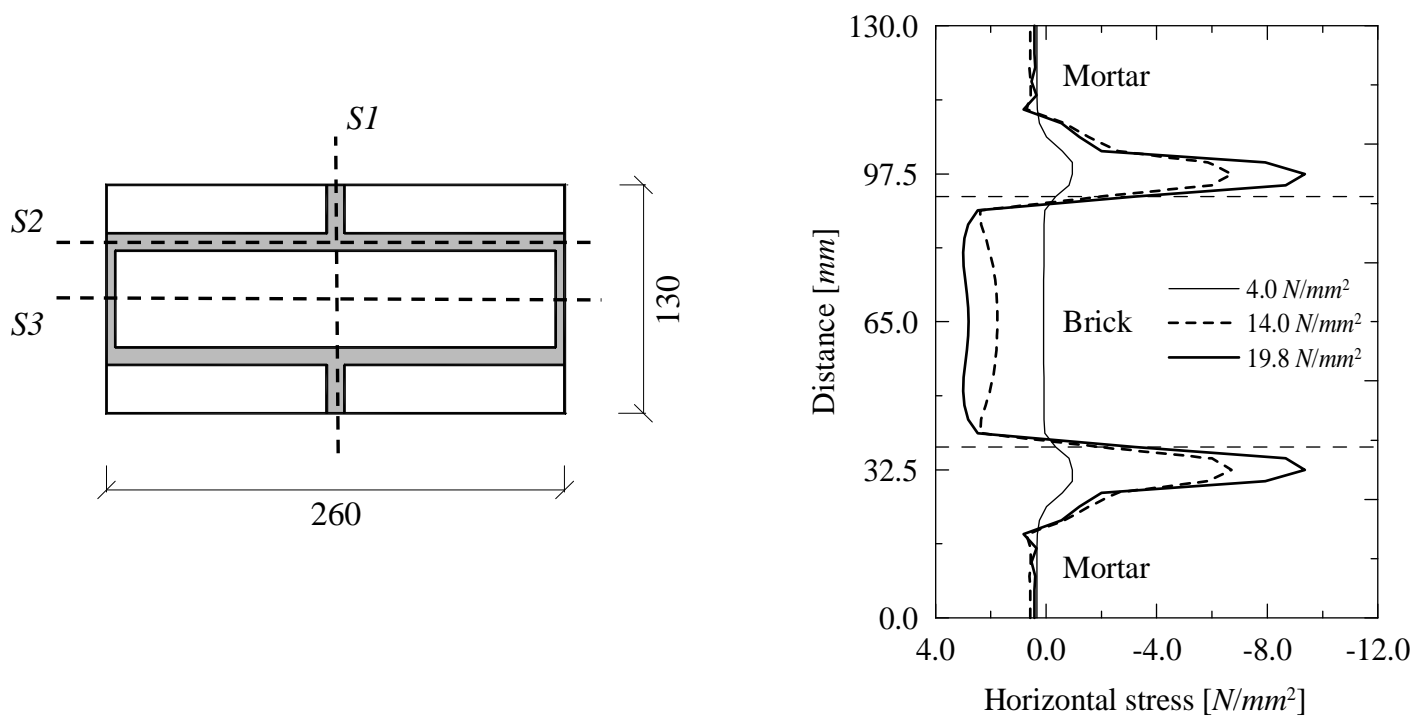

(a)

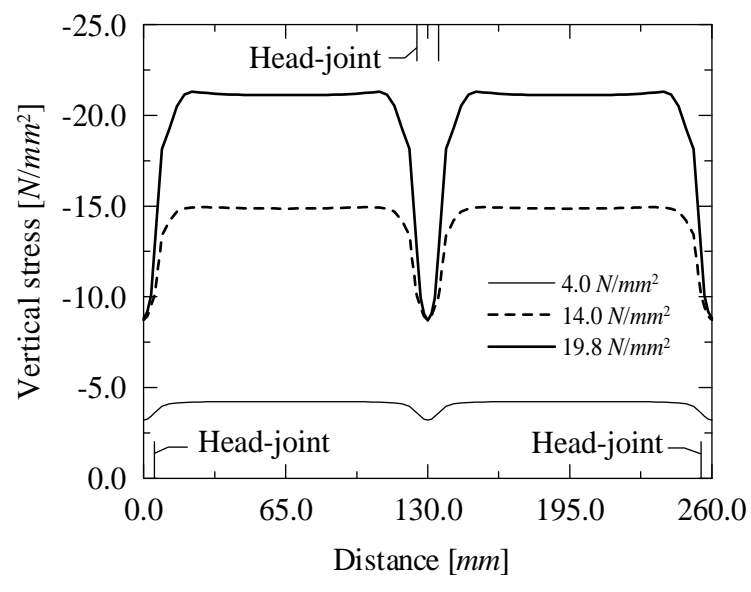

(b)

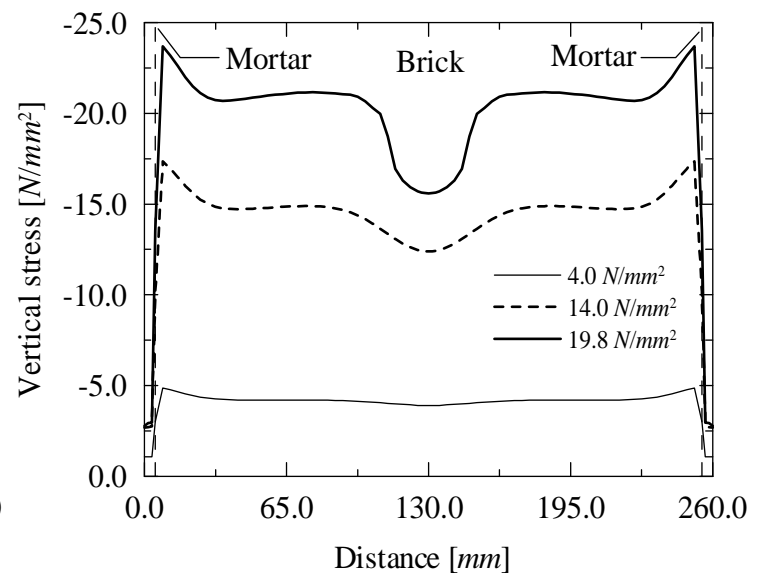

(c)

Figure 14 - Stress diagrams at increasing load levels for different sections of the cell (EPE):

(a) $S 1$, (b) $S 2$ and (c) $S 3$. 
Table 1 - Mechanical properties of the masonry components [17].

\begin{tabular}{|c|c|c|c|c|}
\hline Component & $\begin{array}{c}E \\
{\left[\mathrm{~N} / \mathrm{mm}^{2}\right]}\end{array}$ & $\begin{array}{c}v \\
{[-]}\end{array}$ & $\begin{array}{c}f_{c} \\
{\left[\mathrm{~N} / \mathrm{mm}^{2}\right]}\end{array}$ & $\begin{array}{c}f_{f} \\
{\left[\mathrm{~N} / \mathrm{mm}^{2}\right]}\end{array}$ \\
\hline Unit & 4865 & 0.09 & 26.9 & 4.9 \\
\hline Mortar $M 1$ & 1180 & 0.06 & 3.2 & 0.9 \\
\hline Mortar $M 2$ & 5650 & 0.09 & 12.7 & 3.9 \\
\hline Mortar $M 3$ & 17760 & 0.12 & 95.0 & 15.7 \\
\hline
\end{tabular}


Table 2 - Mechanical properties of the masonry prisms [17].

\begin{tabular}{|c|c|c|c|}
\hline Prism type & Mortar type & $\begin{array}{c}E \\
{\left[N / \mathrm{mm}^{2}\right]}\end{array}$ & $\begin{array}{c}f_{c} \\
{\left[N / \mathrm{mm}^{2}\right]}\end{array}$ \\
\hline$P 1$ & $M 1$ & 1110 & 11.0 \\
\hline$P 2$ & $M 2$ & 2210 & 14.5 \\
\hline$P 3$ & $M 3$ & 2920 & 17.8 \\
\hline
\end{tabular}


Table 3 - Inelastic properties given to masonry components.

\begin{tabular}{|c|c|c|c|c|c|c|}
\hline Component & $\begin{array}{c}c \\
{\left[\mathrm{~N} / \mathrm{mm}^{2}\right]}\end{array}$ & $\begin{array}{c}f_{t} \\
{\left[\mathrm{~N} / \mathrm{mm}^{2}\right]}\end{array}$ & $\begin{array}{c}\sin \phi \\
{[-]}\end{array}$ & $\begin{array}{c}\sin \psi \\
{[-]}\end{array}$ & $\begin{array}{c}G f_{t} \\
{[\mathrm{~N} / \mathrm{mm}]}\end{array}$ & $\begin{array}{c}G f_{c} \\
{[\mathrm{~N} / \mathrm{mm}]}\end{array}$ \\
\hline Unit & 11.3 & 3.7 & 0.17 & 0.09 & 0.190 & 12.5 \\
\hline Mortar $M 1$ & 1.3 & 0.7 & 0.17 & 0.09 & 0.350 & 2.7 \\
\hline Mortar $M 2$ & 5.3 & 3.0 & 0.17 & 0.09 & 0.150 & 10.0 \\
\hline Mortar $M 3$ & 39.9 & 12.0 & 0.17 & 0.09 & 0.600 & 23.0 \\
\hline
\end{tabular}


Table 4 - Adjusted elastic deformability parameters for mortar.

\begin{tabular}{|l|c|c|}
\hline & $E\left[N / \mathrm{mm}^{2}\right]$ & $E_{a d j} / E_{\exp }$ \\
\hline Mortar $M 1$ & 355 & 0.30 \\
\hline Mortar $M 2$ & 735 & 0.13 \\
\hline Mortar $M 3$ & 1065 & 0.06 \\
\hline
\end{tabular}


Table 5 - Values for the parameters $s$ and $t$ of Ohler [12] equation.

\begin{tabular}{|c|c|c|c|}
\hline & $0<f_{c} / f_{c, u}<0.33$ & $0.33<f_{c} / f_{c, u}<0.67$ & $0.67<f_{c} / f_{c, u}<1.0$ \\
\hline$s$ & 0.662 & 0.811 & 1.000 \\
\hline$t$ & 0.662 & 0.960 & 2.218 \\
\hline
\end{tabular}


Table 6 - Values for the parameter $m$ of Ohler [12] equation.

\begin{tabular}{|c|c|c|c|c|}
\hline$f_{c, m}\left[\mathrm{~N} / \mathrm{mm}^{2}\right]$ & 31.6 & 21.4 & 15.4 & 6.4 \\
\hline$m[-]$ & 5.3 & 3.6 & 2.4 & 2.1 \\
\hline
\end{tabular}


Table 7 - Experimental and analytical strength values. In brackets, the ratio between the predicted and experimental strengths is given.

\begin{tabular}{|c|c|c|c|c|c|c|c|}
\hline Prism & $\begin{array}{c}\text { Exp. } \\
{[17]}\end{array}$ & $\begin{array}{c}\text { Francis et } \\
\text { al. }[13]^{1}\end{array}$ & $\begin{array}{c}\text { Khoo \& } \\
\text { Hendry } \\
{[11]}\end{array}$ & $\begin{array}{c}\text { Ohler } \\
{[12]}\end{array}$ & $\begin{array}{c}\text { EC 6 } \\
{[8]}\end{array}$ & $\begin{array}{c}\text { ACI } \\
{[9]}\end{array}$ & $\begin{array}{c}\text { Numerical } \\
\text { simulations } \\
E P E^{1}\end{array}$ \\
\hline$P 1$ & 11.0 & $\begin{array}{c}25.0 \\
(225 \%)\end{array}$ & $\begin{array}{c}15.2 \\
(140 \%)\end{array}$ & $\begin{array}{c}14.8 \\
(135 \%)\end{array}$ & $\begin{array}{c}7.5 \\
(70 \%)\end{array}$ & $\begin{array}{c}9.4 \\
(85 \%)\end{array}$ & $\begin{array}{c}18.2 \\
(165 \%)\end{array}$ \\
\hline$P 2$ & 14.5 & $\begin{array}{c}24.2 \\
(165 \%)\end{array}$ & $\begin{array}{c}20.2 \\
(140 \%)\end{array}$ & $\begin{array}{c}19.0 \\
(130 \%)\end{array}$ & $\begin{array}{c}11.3 \\
(80 \%)\end{array}$ & $\begin{array}{c}11.0 \\
(75 \%)\end{array}$ & $\begin{array}{c}24.1 \\
(165 \%)\end{array}$ \\
\hline$P 3$ & 17.8 & $\begin{array}{c}23.4 \\
(130 \%)\end{array}$ & - & - & $\begin{array}{c}13.0 \\
(75 \%)\end{array}$ & $\begin{array}{c}11.0 \\
(60 \%)\end{array}$ & $\begin{array}{c}30.0 \\
(170 \%)\end{array}$ \\
\hline
\end{tabular}

${ }^{1}$ The given results were obtained with adjusted mortar stiffness values. 